\title{
UNBOUNDED SOLUTIONS FOR BOUNDARY VALUE PROBLEMS OF RIEMANN LIOUVILLE FRACTIONAL DIFFERENTIAL EQUATIONS ON THE HALF-LINE
}

\author{
TUGBA SENLIK CERDIK, FULYA YORUK DEREN AND NUKET AYKUT HAMAL
}

\author{
Department of Mathematics, Ege University, 35100 Bornova, Izmir, Turkey \\ E-mail: tubasenlik@gmail.com, fulya.yoruk@ege.edu.tr, nuket.aykut@ege.edu.tr
}

\begin{abstract}
In this study, a boundary value problem is worked out for fractional differential equations on the half line. Here, some results on the existence of positive solutions are obtained for the fractional boundary value problem and its monotone iterative scheme is established by using the monotone iterative technique.

Key Words and Phrases: infinitive interval, boundary value problem, monotone iterative technique, fixed point.
\end{abstract}

2010 Mathematics Subject Classification: 34B10, 34B18.

\section{REFERENCES}

[1] R.P. Agarwal, M. Benchohra, S. Hamani, S. Pinelas, Boundary value problems for differential equations involving Riemann-Liouville fractional derivative on the half line, Dynamics of Continuous, Discrete and Impulsive Systems Series A: Mathematical Analysis, 18(2011), 235-244.

[2] R.P. Agarwal, S.K. Ntouyas, B. Ahmad, M.S. Alhothuali, Existence of solutions for integrodifferential equations of fractional order with nonlocal three-point fractional boundary conditions, Adv. Difference Equations, 2013, 2013:128.

[3] B. Ahmad, S.K. Ntouyas, A. Alsaedi, New Existence Results for Nonlinear Fractional Differential Equations with Three-Point Integral Boundary Conditions, Adv. Difference Equations, 2011, Article ID 107-384, 11 p.

[4] B. Ahmad, J.J. Nieto, Riemann-Liouville fractional integro-differential equations with fractional nonlocal integral boundary conditions, Boundary Value Problems, 2011, 2011:36.

[5] A. Guezane-Lakouda, R. Khaldi, Solvability of a fractional boundary value problem with fractional integral condition, Nonlinear Anal., 75(2012), 2692-2700.

[6] M. Jiang, S. Zhong, Successively iterative method for fractional differential equations with integral boundary conditions, Applied Math. Letters, 38(2014), 94-99.

[7] A.A. Kilbas, H.M. Srivastava, J.J. Trujillo, Theory and Applications of Fractional Differential Equations, in: North-Holland Mathematics Studies, Vol. 204, Elsevier Science B.V, Amsterdam, 2006.

[8] S. Liang, J. Zhang, Existence of three positive solutions of m-point boundary value problems for some nonlinear fractional differential equations on an infinite interval, Computers and Mathematics with Appl., 61(2011), 3343-3354.

[9] Y. Liu, Existence and uniqueness of solutions for a class of initial value problems of fractional differential systems on half lines, Bulletin des Sciences Math., 137(2013), 1048-1071. 
[10] Y. Liu, B. Ahmad, R.P. Agarwal, Existence of solutions for a coupled system of nonlinear fractional differential equations with fractional boundary conditions on the half-line, Adv. Difference Equations, 2013, 2013:46.

[11] X. Liu, M. Jia, Multiple solutions of nonlocal boundary value problems for fractional differential equations on the half-line, Electronic J. Qualitative Theory of Diff. Equations, 2011, no. 56, $1-14$.

[12] X. Liu, M. Jia, X. Xiang, On the solvability of a fractional differential equation model involving the p-Laplacian operator, Computers and Mathematics with Appl., 64(2012), 3267-3275.

[13] N. Nyamoradi, D. Baleanu, R.P. Agarwal, Existence and uniqueness of positive solutions to fractional boundary value problems with nonlinear boundary conditions, Adv. Difference Equations, 2013, 2013:266.

[14] N. Nyamoradi, T. Bashiri, S.M. Vaezpour, D. Baleanu, Uniqueness and existence of positive solutions for singular fractional differential equations, Electronic J. Diff. Equations, 2014 (2014), no. $130,1-13$.

[15] I. Podlubny, Fractional Differential Equations, Academic Press, San Diego, 1999.

[16] S.G. Samko, A.A. Kilbas, O.I. Marichev, Fractional Integrals and Derivatives: Theory and Applications, Gordon and Breach, Yverdon, 1993.

[17] X. Su, S. Zhang, Unbounded solutions to a boundary value problem of fractional order on the half line, Computers and Mathematics with Appl., 61(2011), 1079-1087.

[18] Y. Wang, L. Liu, Y. Wu, Extremal solutions for p-Laplacian fractional integro-differential equation with integral conditions on infinite intervals via iterative computation, Adv. Difference Equations, 2015, 2015:24.

[19] X. Zhang, Existence and iteration of positive solutions for high-order fractional differential equations with integral conditions on a half-line, J. Applied Mathematics and Computing, 45(2014), 137-150.

Received: October 8, 2015; Accepted: February 10, 2016. 